\title{
PARA COMPRENDER LA FALSA "PANDEMIA COVID-19" UNA EXPLICACIÓN DESDE LA FILOSOFÍA POLÍTICA DE ARISTÓTELES
}

\author{
UNDERSTADING THE FALSE “COVID-19 PANDEMIC” AN EXPLANATION FROM \\ ARISTOTLE'S POLITICAL PHILOSOPHY
}

Jesús Manuel Araiza

Es miembro del Programa de Posgrado en Filosofía de la Universidad Nacional Autónoma de México (UNAM) y Profesor en el Instituto de Humanidades y Ciencias Sociales de la Universidad Autónoma del Estado de Morelos

(UAEM), México, así como también en la Facultad de Derecho y Ciencias Sociales de esta misma Universidad.

Miembro del Sistema Nacional de Investigadores (SNI) Nivel I. Es Doctor en Filosofía por la Eberhard Karls Universität Tübingen, Alemania, con estudios de Maestría en Letras Clásicas por la Universidad Nacional Autónoma de México y Licenciado en Ciencia Política por esta misma Universidad.

E-mail: araimar_jes@yahoo.com.mx

Convidado

RESUMO: A principios del año 2020 una declaración de "pandemia" azotó al mundo entero. Desde las oficinas de la Organización Mundial de la Salud (OMS= World Health Organization) se hizo la advertencia, al menos a 193 naciones en el mundo, de la existencia de un -en apariencianuevo y desconocido corona virus. Cómo, en dónde, cuándo y por qué causa se originó, son circunstancias que habrá qué discutir en ulterior ocasión. A partir de ese momento se inició un período de aislamiento social y de autoaislamiento en todas las naciones por instrucciones y conminación de la OMS, bajo la advertencia de que solo así sería posible mantener a la población a salvo del contagio, de la enfermedad o del posible efecto letal del virus sobre los más vulnerables o sobre la población en general. ¿Cómo se explica esta declaración de pandemia que ha generado -aun en la población física y mentalmente sana del mundo entero en el ámbito psíquico- miedo, ansiedad, pánico, terror, desconfianza mutua, auto aislamiento, debilitamiento emocional, estrés, depresión, y, en el ámbito de la economía familiar, pérdida de empleo y en muchos casos un mayor empobrecimiento? Dar una respuesta a tales cuestiones es el propósito de nuestra presente investigación. Nuestra hipótesis toma el punto de partida de que los mismos artilugios que de ordinario se emplean desde antiguo para preservar el poder en una tiranía, han sido implementados actualmente hacia la población del mundo entero para mantener el poder de un imperio oligárquico sobre la totalidad del globo terráqueo. En nuestra argumentación tomamos como marco teórico de referencia, los principios de la filosofía política de Aristóteles expuestos en su tratado de la Política, libro V capítulo 9.

Palabras clave: Miedo, ansiedad, pánico, terror, desconfianza mutua, aislamiento social, debilitamiento emocional, depresión, empobrecimiento, falsa pandemia Covid-19, oligarquía 
tiránica de los EEUU, PCCh, China, filosofía política de Aristóteles.

ABSTRACT: At the beginning of 2020 a declaration of a "pandemic" stopped the entire world. From the offices of the World Health Organization (WHO), at least 193 nations in the world were warned of the existence of a new and apparently unknown corona virus. How, where, when and why it originated, are circumstances that will have to be discussed at a later time. From that moment on, a period of social isolation and self-isolation began in all nations on the instructions and injunction of the WHO, under the warning that only in this way would it be possible to keep the population safe from contagion, of the disease or the possible lethal effects of the virus on the most vulnerable or on the population in general. How do you explain this declaration of a pandemic that has generated - even in the physically and mentally healthy population of the entire world in the psychic sphere - fear, anxiety, panic, terror, mutual distrust, self isolation, emotional weakness, stress, depression, and, in the area of the family economy, loss of employment and in many cases greater impoverishment? Giving an answer to such questions is the purpose of our present investigation. Our hypothesis takes the starting point that the same devices that are ordinarily used since ancient times to preserve power in a tyranny, have now been implemented towards the population of the entire world to maintain the power of an oligarchic empire over the entire globe. In our argumentation we take as a theoretical frame of reference, the principles of Aristotle's political philosophy set forth in his treatise on Politics, book V chapter 9.

Keywords: Fear, anxiety, panic, terror, mutual mistrust, social isolation, emotional distress, depression, impoverishment, fake Covid-19 pandemic, tyrannical oligarchy of the USA, Communist Party of China, China, Aristotle's political philosophy.

SUMÁRIO: Introducción. 1 Algunas opiniones críticas y sensatas de especialistas de la medicina y la psicología. 2 Qué vamos a decir nosotros desde la filosofía política: a) El contexto geopolítico mundial. b) Avaricia y especies de avaricia. c) Oligarquía extrema y tiranía. 3 La falsa pandemia Covid-19: artilugio político para someter a la población del mundo. Conclusiones preliminares. Referencias.

"Así como, en efecto, el ser humano en su perfección es el mejor de los animales, así también, separado de la ley y la justicia, es el peor de todos". Aristóteles, Política I 2, $1253^{\mathrm{a}} 31$.

\section{INTRODUCCIÓN}

Nunca antes en nuestra época contemporánea había parecido como ahora tan oportuno advertir la vigencia de la filosofía política de Aristóteles. Al gran filósofo Estagirita debemos la determinación específica del ánthrōpos, del ser humano, como un animal político por naturaleza ${ }^{1}$. Gracias a que, según nos dice, ya desde su nacimiento - a diferencia de los demás animales -, viene dotado de la capacidad de la palabra, por su capacidad de hablar le es posible la percepción

1 “ho ánthrōpos phýsei politikón zôion". Pol. I 2, 1253a 2, cfr. 1253a 7. 
y el discernimiento de lo bueno y de lo malo, de lo conveniente y lo nocivo, de lo justo y de lo injusto. Que sea político por naturaleza significa que su esencia se da en el vivir dentro de la pólis, de la comunidad política por excelencia; indica, en efecto, que es gregario e inclinado a la vida social mucho más que las abejas o que cualquier otro animal gregario, gracias a la posesión de la palabra, el lógos. Pues, frente a los demás animales esto es lo peculiar a los seres humanos: el poseer, como único ser viviente, la percepción de lo bueno y de lo malo, de lo justo y de lo injusto, de lo conveniente y lo pernicioso, y de las demás cualidades contrarias. Pero, si nace provisto de las armas para la prudencia y la excelencia, también le es posible emplearlas totalmente para los fines contrarios. Pues, tal como afirma nuestro filósofo "así como el ser humano en su perfección es el mejor de los animales, así también, separado de la ley y la justicia, es el peor de todos"2. Así pues, si lo más propio del ser humano es la vida en común, allí donde puede alcanzar perfección y bienestar, y si por naturaleza tiende hacia el contacto social, a comunicarse a través de la palabra, al discernimiento de lo bueno y de lo malo, de lo conveniente y lo nocivo ¿cómo se explican entonces las medidas de restricción social, de comunicación y de convivencia que han sido impuestas a la población de prácticamente el mundo entero, si es evidente que ocurre que la inhibición de tales actividades afecta precisamente la esencia del ser humano? Pues restrictivas y prohibitivas medidas tales como el aislamiento, el distanciamiento, el uso de cubre bocas (barbijos o mascarillas), de viseras o plásticos transparentes inhiben el despliegue de las facultades propias del ser humano, correlativas al uso de la palabra. Al taparse la boca, en efecto, al distanciarse de los demás, al evitar la comunicación verbal y directa, se inhibe y reprime la tendencia propia del ser humano a socializar y a ser él mismo lo que es: un animal político por naturaleza.

Pues bien, la tarea de la ciencia política es explicar por sus causas los fenómenos que ocurren en el ámbito de la comunidad política, tanto en la vida interna de la comunidad misma -en la relación entre gobernantes y gobernados-, como en sus relaciones externas con los demás Estados. Ahora bien, en el así llamado "mundo globalizado" hay decisiones que se toman y ejecutan desde un gobierno centralizado que afectan a la mayoría de los países del mundo. Parece corresponder entonces a la ciencia política y a ninguna otra ciencia, el explicar por sus causas todo lo que ocurre en ese entorno mundial, qué ocurre, por qué, quién o quiénes y con qué finalidad toman decisiones de alcance global.

Pues bien, a principios del año 2020 desde las oficinas de la Organización Mundial de la Salud (OMS) sorprendió al mundo entero una declaración de "pandemia" provocada presuntamente por una especie de corona virus en ese entonces, según se decía, aún desconocida. A partir de ese momento, por instrucciones de la OMS comenzaron a tomarse prácticamente en todos los países miembros de la Organización de las Naciones Unidas (ONU) medidas restrictivas en la vida social -como el aislamiento, el distanciamiento, el uso de cubre bocas (barbijos o mascarillas), de viseras o plásticos transparentes, $\mathrm{y}$, a través de todos los medios de comunicación disponibles, se emprendieron sobre la población bombardeos y campañas abrumadoras desde los gobiernos de todos los niveles -federal, estatal o municipal-, con frecuencia de acoso o el uso de la fuerza, con la insistente conminación a permanecer en casa. Muy pocos pudieron sustraerse al vertiginoso y eficaz impacto de tales campañas de aislamiento social, autoaislamiento y distanciamiento ordenados desde el organismo que norma, ordena y vigila a nivel mundial, bajo el amparo de la ONU, el orden en materia de salud pública. Reconocidos médicos, virólogos, epidemiólogos e incluso economistas de diversas nacionalidades, ajenos a la OMS o a los intereses de los gobiernos supeditados a este organismo, han mostrado desde un inicio y en el curso de los acontecimientos su extrañeza, inconformidad o desaprobación ante aquello que consideran una errónea conducción de la presunta pandemia. Pero ¿cómo se explica esta declaración de pandemia

${ }^{2}$ Pol. I 2, $1253^{\text {a }} 31$. 
que ha generado en el ámbito psíquico - aun en la población física y mentalmente sana del mundo entero- miedo, ansiedad, pánico, terror, desconfianza mutua, auto aislamiento, debilitamiento emocional, estrés o depresión, y, en la esfera de la economía familiar, pérdida de empleo y en muchos casos pobreza o un mayor empobrecimiento ${ }^{3}{ }_{¿}$ Cuáles son las motivaciones verdaderas detrás de una declaratoria de esta índole, no libre de contradicciones, carente de argumentos y, especialmente por ello, apoyada en el enorme poder de los grandes medios masivos de comunicación en todos los niveles y en el ejercicio de un centralizado poder político-económico desde la OMS? Pues bien, dar una breve respuesta a tales cuestiones desde la perspectiva de la ciencia política, en especial desde la filosofía política del Estagirita, es el propósito de nuestra presente investigación.

\section{ALGUNAS OPINIONES CRÍTICAS Y SENSATAS DE ESPECIALISTAS DE LA MEDICINA Y LA PSICOLOGÍA}

"La pandemia del Coronavirus no es una expresión de filantropía, sino de crueldad hacia los seres humanos"4. Franz Ruppert

En primer lugar, hemos de considerar algunas opiniones dignas de tomar en cuenta. De entre las opiniones más sensatas que han planteado dudas o se han pronunciado en contra de las medidas restrictivas ordenadas por la OMS, destacan las de médicos alemanes como Heiko Schöning y Bodo Schiffmann y el médico austriaco Martin Haditsch, los tres miembros del Comité de Investigación Extra-parlamentario del Corona (ACU: Außerparlamentarischer Corona Untersuchungsausschuss) ${ }^{5}$.

- Schöning expresa serias dudas de si la forma en que se han tomado las medidas restrictivas han sido en verdad proporcionadas a la magnitud y naturaleza del supuesto riesgo ante el virus. Dice, en efecto, "los datos científicos muestran que no existe una base para estas medidas"; anuncia la necesidad de convocar a científicos de todas las ramas a discutir sobre tales medidas restrictivas, y manifiesta su preocupación de que "nuestros hijos estén sufriendo ahora, no solo porque los patios de recreo han sido cerrados, sino porque están separados unos de los otros. Y para los adultos es aún peor. Nos preguntamos ¿por qué a los familiares ya no se les permite visitar a sus padres, por ejemplo, en el hogar de ancianos? ¿Existe un peligro tan grande de infección? ¿Realmente tenemos un virus asesino aquí? ${ }^{6}$ ¿Tenemos la rabia o tenemos la plaga?

\footnotetext{
${ }^{3}$ El Prof. Dr. Franz Ruppert nos ofrece una esquemática pero completa y clara explicación de estos efectos nocivos a la salud emocional en su trabajo "Impacto de la pandemia del coronavirus en la salud mental", en https://acu2020.org/es/. A su trabajo debemos toda las referencias bibliográficas añadidas al final de este escrito, relativas a la salud mental. Video también en https://www.youtube.com/watch?v=S63hwuSBGHs

4 “Impacto de la pandemia del coronavirus en la salud mental”, pág. 12 (en https://acu2020.org/es/). Video en https://www.youtube.com/watch?v=S63hwuSBGHs

${ }^{5}$ Muchas más pueden verse en la página del Comité (ACU: Außerparlamentarischer Corona Untersuchungsausschuss) https://acu2020.org/es

${ }^{6}$ Que no es letal puede verse por el hecho de que no todos los que se infectan enferman ni mueren. Según cifras que han proporcionado, de mil seres humanos que dan positivo al covid-19 muere uno (es decir, en $0.01 \%$ la enfermedad es mortal). Por tanto, la llamada pandemia del Covid-19 presenta muchas dudas. Según declaraciones del coronel ruso Vladimir Kvachkov se trata de una falsa pandemia. De manera razonable sugiere que este fenómeno ha de analizarse no como un fenómeno de salud pública, sino desde la perspectiva de los poderes globales, religiosos, políticos,
} 
¡Tenemos serias dudas de que sea así! ¡No tenemos la plaga!”. De manera que invoca a la honestidad y a la transparencia como algo que realmente ayuda. "Queremos garantizar esta honestidad". 7 Veremos que no debemos tener más miedo, como hemos estado con olas de gripe normales en los últimos años, porque así es exactamente como parece $\operatorname{ser}^{8}$. Ante las medidas terribles que en Alemania se han tomado, el Dr. Schöning denuncia, a partir de un informe interno del mismo Ministerio Federal del Interior que el $90 \%$ de todas las operaciones necesarias en ese país no se llevaron a cabo, lo cual afectó a 2,5 millones de personas (de hecho esta postergación de atención a enfermos de otros padecimientos se replica en todos los países). Y también que, según el mismo informe, entre 5,000 y 125,000 pacientes han muerto o están falleciendo, como resultado de las medidas del gobierno. La pregunta que se plantea es, entonces ¿por qué han tomado estas terribles medidas y quién se beneficia con ellas?

- El Dr. Bodo Schiffmann ${ }^{9}$ denuncia la restricción permanente e injustificada de los derechos fundamentales; el uso de las cifras de enfermos o infectados, que solo generan miedo, pues solo suman los casos de enfermedad y no muestran que haya una desproporción entre el número de personas evaluadas y las realmente infectadas. "Lo único que viene del gobierno, es la constante llamada a la vacunación para una enfermedad de la cual, ahora sabemos muy bien a través de muchos estudios internacionales, que es muy comparable con la gripe, que las tasas de mortalidad no son más altas que las de fuertes olas de gripe, y que las medidas no pueden justificarse por esto". Veo el peligro de la pérdida de la democracia, y veo cada vez más esfuerzos para convertir nuestro orden democrático libre, en un estado de vigilancia, con control mental y aplicaciones de vigilancia y similares, bajo la apariencia de leyes de protección contra infecciones. Denuncia que todas las medidas que se han tomado se han desarrollado en el contexto de un escenario de terror que nunca se materializó, y que, sin embargo, se mantiene constantemente alto para crear el miedo entre la población de una enfermedad mortal que no existe en esta forma. Exige, asimismo, el fin inmediato del estado de emergencia, el fin de la obligación de usar mascarillas, pues "en un momento en que ya no había más casos de enfermedad, se creó la obligación del uso de mascarillas el 29 de mayo de este año". ${ }^{10}$ Finalmente, expone que en la aplicación de las medidas se muestra una ignorancia aterradora, pues no se toma en cuenta ni reconocidos estudios internacionales ni a expertos de todos los campos -virólogos, bacteriólogos, epidemiólogos o incluso economistas-, a quienes o no se les escucha o se les llama mentirosos, charlatanes, o teóricos de la conspiración.

- El Dr. Haditsch"11 denuncia que "se han tomado decisiones irresponsablemente inapropiadas, que también han socavado los derechos democráticos fundamentales y pisoteado los deberes éticos bajo los pies; actualmente hay una constante creación de los peores escenarios posibles

\footnotetext{
financieros, económicos y nacionales. Ha de considerarse como una estrategia global, como ejercicios militares de comando por parte de los poderes ocultos que controlan a la humanidad. Cf. https://www.youtube.com/watch?v=pOTK 7vGDXE

${ }^{7}$ https://acu2020.org/es/

${ }^{8}$ Cfr. la opinión del Dr. Bhakdi. No se ha comprobado que el virus sea letal. Mansmann vs. Bhakdi: Corona schon vorbei? DW Nachrichten. https://www.youtube.com/watch?v=YWOLsC31grI

${ }^{9}$ Médico especialista en otorrinolaringología.

${ }^{10}$ https://acu2020.org/es/ A modo de ejemplo cuestiona el hecho de que "En las últimas semanas -hoy es 20 de junio de 2020- tuvimos grandes manifestaciones masivas contra el racismo en 20 ciudades alemanas con más de 20,000 participantes; si este virus en esta forma con esta tasa de infección estuviera presente todavía en Alemania, entonces deberíamos poder registrar un aumento masivo en el número de infecciones hoy, pero este no es el caso".

${ }^{11}$ Médico general, de Austria, y especialista en microbiología, virología y epidemiología de la infección.
} 
por parte de los medios de comunicación, a la promoción del miedo con comparaciones inapropiadas; representaciones inadecuadas y evidentes tendencias amenazantes, que en la práctica nunca se materializaron; este enfoque despectivo de la salud y de los seres humanos está en marcado contraste con la comprensión profesional y ética para todos nosotros. Este miedo permanente, o más bien uno podría decir el pánico, el daño psicológico y social que se puede deducir de él, el gigantesco daño médico y económico y, por último, pero no menos importante, los masivos ataques en toda nuestra vida cultural y de ocio es, creo, al menos como un médico holísticamente orientado, razón suficiente y motivación suficiente para ponerse de pie y luchar contra esta locura". En vista del desastre, que no puede evaluarse en absoluto en la actualidad, parece necesario -dice-, con el debido respeto, por supuesto, pero sin ambigüedades, presionar para una evaluación objetiva de estas decisiones y llamar a los que toman las decisiones para que rindan cuentas en caso de que se pueda comprobar una mala conducta.

\section{QUÉ VAMOS A DECIR NOSOTROS DESDE LA FILOSOFÍA POLÍTICA:}

\section{a) El contexto geopolítico mundial}

En vista del orden geopolítico de nuestro mundo contemporáneo, de un mundo globalizado en el que predominan la usura, el mercantilismo y la comercialización de todos los bienes materiales e incluso humanos por la búsqueda de ganancias medibles en dinero (sea mediante el engaño, la corrupción o el uso de la fuerza militar), nos sentimos obligados en nuestro análisis a considerar la hipótesis de que la declaración de la pandemia del Covid-19 es en realidad un artificio político que esconde intenciones oscuras que es preciso develar.

Pues bien, las oligarquías predominantes, en especial las norteamericanas (republicanos y demócratas) - pero también las oligarquías de Canadá, de Inglaterra, Francia e Israel, entre otras-, tienen la habilidad retórica de hacer pasar por bueno lo malo. Se quiere hacer creer, por ejemplo, que los países llamados del "primer mundo" como los Estados Unidos de Norteamérica, como Canadá, Inglaterra, Francia y otros más son democracias y que tienen la virtud ética de la liberalidad. En realidad se trata de gobiernos oligárquicos, fundados sobre el principio de la avaricia $^{12}$ y de la búsqueda ilimitada de riqueza y de ganancia en todas sus transacciones. Pues en ellos se busca sobre todo el beneficio exclusivo de las clases poderosas en el ámbito financiero, las cuales se constituyen de muy pocos, en perjuicio de la mayoría de la población ${ }^{13}$. De hecho las clases oligárquicas que dominan en los gobiernos de esos países son depredadoras, coercitivas y extorsivas en su relación con los países menos poderosos. Otro ejemplo de engaño propio de las oligarquías, es esconder bajo el manto de una enorme generosidad y filantropía sus pretensiones de codicia, como es el caso del multimillonario y avaro Bill Gates, quien como individuo pone al servicio de la Organización Mundial de la Salud aportaciones económicas más cuantiosas que un país entero ${ }^{14}$, con el derecho velado de reclamar ganancias mediante la creación y venta de vacunas

\footnotetext{
${ }^{12}$ Cf. Aristóteles, Ética Nicomáquea IV 1, 1119b 30 “Atribuimos siempre la avaricia a los que se esfuerzan por los bienes económicos más de lo que conviene".

${ }^{13}$ Una democracia, literalmente es el gobierno del pueblo. Y el pueblo se compone en su mayoría casi siempre de pobres (Cf. Arist. Pol. IV 4, 1291 b 30ss.). De ahí se sigue, pues, que donde se gobierna en perjuicio de los pobres para beneficio de los pocos ricos no hay una democracia sino un gobierno oligárquico. Cf. Arist. Pol. IV 5, 1292 ${ }^{\text {a }} 39$ ss.

${ }^{14}$ Según datos de la OMS, el Estado que más contribuyó antes de la declarada pandemia covid-19, fue Estados Unidos, país que en el bienio 2018-2019, aportó en torno al 16\% de la financiación total. El segundo mayor financiador fue la Fundación Bill y Melinda Gates, que en el mismo periodo aportó alrededor del 9\%. Tras la decisión de Donald Trump el 14 de abril del año 2020 de suspender el financiamiento oficial del gobierno de los Estados Unidos, el que más aporta a la OMS es el norteamericano Bill Gates a través de su fundación, con una cantidad superior a la que aportan Reino Unido, Alemania, Japón y la ONU. https://elordenmundial.com/financiacion-organizacion-mundial-salud-oms/
}

Revista de Direito Brasileira | Florianópolis, SC | v. 26 | n. 10 | p. 441-456 | Mai./Ago. 2020 
a la población mundial y de ganar el reconocimiento público de salvador de la humanidad (En realidad su inversión en vacunas supone un mercado potencial de al menos 7, 300 millones de clientes cautivos, el total de los habitantes del globo terrestre en la actualidad). O como el caso del húngaro judío de origen, George Soros, quien pretende hacer creer que tiene una fundación sin fines de lucro y que realiza labor filantrópica con migrantes empobrecidos, cuando él mismo no consagra su existencia a otro fin que al de acumular dinero de manera ilimitada.

No conviene pasar por alto que el globo terráqueo se encuentra políticamente organizado bajo un predominio oligárquico a partir del orden impuesto tras el término de la Segunda Guerra Mundial. Es de todos sabido que la potencia político, militar y económicamente más poderosa son los Estados Unidos de Norteamérica; de modo que, con éstos a la cabeza, reunidos en la Organización de las Naciones Unidas, el país económica y militarmente más poderoso impone sus decisiones a los más débiles. ${ }^{15}$

Y puesto que el sistema de la llamada globalización que los rige se funda en la búsqueda de ganancia y de una ilimitada riqueza, resulta paradójico que la propagación de un coronavirus haya dado lugar a que el intercambio comercial entre todos los países del mundo prácticamente se detuviera. Pues la paralización del comercio mundial y de las transacciones entre todos los países supondría pérdidas económicas para todos. Tanto más sospechosa resulta la decisión de la OMS, cuanto que no se ha demostrado que el mencionado coronavirus sea tan letal y tan peligroso para la vida humana como para aislar (como han dispuesto desde la Organización Mundial de la Salud) y como para mantener confinada en sus casas a prácticamente toda la población del planeta entero, es decir, a más de siete mil millones de seres humanos por la muerte de apenas un millón de personas en el mundo, una cantidad ínfima y hasta ahora de ninguna manera alarmante, pues el riesgo de morbilidad y mortalidad de un coronavirus equiparable a una gripe, no parece corresponderse proporcionalmente con las consecuencias y daños que ya reporta y seguirá reportando un absurdo confinamiento sobre la salud física y mental de la población del mundo entero.

¿Qué se pretende cuando toman medidas de tal índole y de tanta magnitud al punto que paralizan aquello que ha sido el motor de las relaciones de lucro entre los países durante al menos 75 años? ¿Por primera vez en quinientos años los gobiernos oligárquicos, en especial los de los Estados Unidos, Inglaterra, Francia y ahora también China ${ }^{16}$, estarán preocupados por salvaguardar a la humanidad de una enfermedad que no es letal, aun a costa de enormes pérdidas económicas? ${ }^{17}$ Resulta difícil suponer, en efecto, que en un ámbito de relaciones internacionales basadas en la avaricia y en donde prevalece la búsqueda ilimitada de riqueza y el imperio de las finanzas, aquellos que establecen las leyes y normas serían dañados por medidas tomadas por ellos mismos. El motor de un gobierno oligárquico, en efecto, es la avaricia, y el fin por el que se instala este régimen es la ganancia. Pero ¿qué es la avaricia?

\footnotetext{
${ }^{15}$ El concierto y los acuerdos de las Naciones Unidas (sobre todo en decisiones de orden militar y de ataques bélicos) entre las cuales se supone un respeto de igual a igual y una manera democrática, nos hace recordar, en efecto, la fábula de Antístenes, según la cual, reunidos los animales en la selva, al reclamar las liebres derechos iguales para todos, replican los leones: "y dónde están vuestras garras y vuestros dientes"? (Arist. Pol. III 13, 1284a 15).

${ }^{16}$ Desde que China dio el primer paso en 1978 para ingresar como un rival y un fuerte competidor frente a los Estados Unidos de Norteamérica, han pasado 42 años de un período de cincuenta años que está por cumplirse, para cumplir con el fin trazado de llegar a ser la primer potencia comercial en el mundo, desplazando a los Estados Unidos de ese lugar. Una especial atención merece, en efecto, la apertura comercial de China que, tras la muerte de Mao Tse Tung, emprende su sucesor Deng Xiaoping hacia los mercados occidentales en un marco de libre comercio, y luego el posterior y vertiginoso robustecimiento como potencia mundial en franca competencia con el imperio estadounidense.

${ }^{17}$ Algunos de los especialistas más sensatos advierten que no es necesario aislar a los seres humanos sanos y que en realidad el coronavirus no es letal para quien tiene un buen sistema inmunológico. Sin embargo, como afirma el Dr. Shiva hay una falsa ciencia del sistema inmunológico: https://www.youtube.com/watch?v=pckCJTfdmGQ
}

Revista de Direito Brasileira | Florianópolis, SC | v. 26 | n. 10 | p. 441-456 | Mai./Ago. 2020 


\section{b) Avaricia y especies de avaricia}

La avaricia, como todas las demás disposiciones habituales del carácter humano, se analiza dentro del ámbito de la ética. Es un vicio con relación al uso del dinero y de los bienes económicos. El avaro es el que o no gasta en absoluto o gasta poco; es el que no gasta en las cosas que conviene, ni cuantas conviene, ni cuando conviene ${ }^{18}$. Tal como explica Aristóteles, hay muchas clases de avaricia; pues los hombres son avaros ya sea por deficiencia en el dar o por exceso en el tomar.

"Los que son deficientes en el dar son llamados tacaños, mezquinos o ruines. No codician lo ajeno ni quieren tomarlo; unos, por cierta especie de justicia equitativa y por cautela de las cosas vergonzosas (hay, en efecto, avaros que parecen o dicen estar vigilantes, para no verse obligados a cometer alguna vez algo vergonzoso; entre ellos se encuentra el "parte cominos" y todos los de tal índole; y han sido llamados así por su exageración en no dar nada); otros por temor se abstienen de las cosas ajenas, en la idea de que no es fácil que uno tome de las cosas de los demás, sin que los otros tomen de las cosas de uno; les agrada, entonces, no tomar ni dar.

En cambio, los que se exceden en tomar toman de todas partes y todo, por ejemplo los que realizan actividades no libres, como los que se prostituyen $\mathrm{y}$ todos los de tal índole, y los usureros que por una pequeña cantidad obtienen mucho. Todos éstos toman de donde no conviene y cuanto no conviene. Común a todos ellos es el lucro vergonzoso. Pues todos actúan con vistas a la ganancia, y por pequeña que sea, soportan una injuria.

Pues a los que toman grandes riquezas de donde no conviene y las que no conviene, como los tiranos que saquean ciudades y despojan templos, no los llamamos avaros, sino más bien malvados, impíos e injustos. En cambio, el jugador, el ratero de ropa y el ladrón están entre los avaros, pues son gananciosos de lo vergonzoso. Pues ambos actúan con vistas a la ganancia y soportan la injuria, unos exponiéndose a los mayores peligros por el botín, y otros lucrando de los amigos, a los que conviene dar. Ambos al querer sacar ganancias de donde no conviene, son codiciosos de lo vergonzoso, y todas estas son obtenciones propias de la avaricia". ${ }^{19}$

Pues bien, del estudio de la historia política de los Estados Unidos de Norteamérica es fácil advertir que la forma de gobierno que los rige desde su nacimiento hasta la actualidad es la de una forma oligárquica. Pues el fin que determina su constitución política es la búsqueda de la ganancia económica y de los bienes materiales. Y si bien las clases ricas se dividen conforme a su actividad económica - unos se dedican a obtener ganancias mediante la especulación de bienes raíces o mediante la industria, otros mediante el comercio o mediante bienes y servicios, otros a través de la minería o el petróleo- la clase más poderosa hoy en día parece ser la que posee inversiones en tecnología y en las finanzas. El lucro vergonzoso y el préstamo con interés es, por tanto, el que prevalece también como norma en el orden de las relaciones internacionales. En este

\footnotetext{
${ }^{18}$ Cf. Aristóteles, Magna Moralia I 23, 1192a 2 ss.

${ }^{19}$ Ética Nicomáquea IV 1, $1121 \mathrm{~b} 21-1122^{\mathrm{a}} 13$.
} 
horizonte, para emplear las palabras de Aristóteles, "como los tiranos que saquean ciudades y despojan templos, no los llamamos avaros, sino más bien malvados, impíos e injustos".

\section{c) Oligarquía extrema y tiranía}

De las cuatro especies de oligarquía ${ }^{20}$ que distingue Aristóteles, la última y la más tensa replica los vicios de los gobiernos tiránicos ${ }^{21}$. Si bien una tiranía es el ejercicio despótico del poder de un solo hombre, y la oligarquía lo es de unos pocos ricos, ambos comparten el carácter injusto de gobierno, pues en ambos se ejerce el poder de manera despótica, es decir, ejercen el gobierno como si les perteneciera absolutamente, para beneficio exclusivo de quien gobierna en perjuicio de los gobernados o en contra de la voluntad de estos. No es la ley la que regula la vida pública, sino la voluntad del monarca en la tiranía, o de los pocos ricos en la oligarquía, para provecho de sí mismos. ${ }^{22} \mathrm{Y}$ el lugar que entre las formas de oligarquía ocupa esta última forma, ese mismo lugar ocupa entre las monarquías la tiranía.

Pues bien, la oligarquía norteamericana, a la cabeza de las demás oligarquías del mundo auto llamadas "democracias", parece encontrarse en la categoría del cuarto tipo clasificado por Aristóteles, una oligarquía que con relación a las distintas formas de oligarquía, es análoga a la tiranía en relación con las distintas formas de monarquía.

\section{LA FALSA PANDEMIA COVID-19: ARTILUGIO POLÍTICO PARA SOMETER A LA POBLACIÓN DEL MUNDO}

Cualquier lector ajeno a la filosofía o que no esté familiarizado en particular con la filosofía de Aristóteles -aun alguno incluso que se precie de serlo-, se asombrará de poder advertir, desde la situación actual de confinamiento social en que nos encontramos, la enorme familiaridad con que puede comprenderse la situación actual de aislamiento social, a partir de la explicación teórica que nos da nuestro filósofo sobre los preceptos habituales para preservar la tiranía. Basta, en efecto, con echar una mirada a su capítulo 9 del libro V de La Política (donde nos ofrece una exposición teórica e histórica de los artilugios tradicionalmente orientados a mantener un gobierno tiránico), para comprender, gracias a su explicación, las motivaciones y naturaleza de las medidas restrictivas actuales que, al menos a los hombres más críticos y que han expresado su desacuerdo en diferentes partes del mundo, parecen propias no de sentimientos filantrópicos, sino de un régimen tiránico y violatorias de los derechos propios de una democracia.

Tanta es la similitud y cercanía entre ambas, que, basta con apenas echar una mirada a las circunstancias de prohibición y restricción a las que ha sido sometida la población en el mundo, y con mirar, a su vez, las medidas que suelen tomarse en las tiranías con vistas a preservar el poder, para advertir de inmediato el hecho de que se trata de una y la misma cosa. Por ello es tan pertinente

\footnotetext{
${ }^{20}$ Cf. Pol. IV 5, 1292 39 ss. "En cuanto a las formas de oligarquía, una es la que hace depender las magistraturas de rentas tan altas que los pobres, no participan, aun siendo muchos, pero el que las adquiere puede participar del gobierno. Otra se da cuando las magistraturas dependen de rentas elevadas y ellos mismos eligen a los que deben ocupar los cargos vacantes ( $s i$ hacen la elección entre todos ellos, éste parece ser un régimen más bien aristocrático, y si la hacen entre algunos determinados, oligárquico). Otra forma de oligarquía es cuando el hijo sucede al padre. La cuarta [especie de oligarquía], existe cuando se da lo que ahora fue dicho, y gobierna no la ley sino los magistrados. Y ésta es correlativa entre las oligarquías, tal como la tiranía lo es entre las monarquías, y la última forma de democracia de la que hablamos, lo es entre las democracias. Y llaman a la oligarquía de tal índole dinastía".

${ }^{21}$ Cf. Pol. IV 5, 1292 b 6.

22 1292b 6: La cuarta [especie de oligarquía], existe cuando se da lo que ahora fue dicho, y gobierna no la ley sino los magistrados. Y ésta es correlativa entre las oligarquías, tal como la tiranía lo es entre las monarquías, y la última forma de democracia de la que hablamos, lo es entre las democracias. Y llaman a la oligarquía de tal índole dinastía.
}

Revista de Direito Brasileira | Florianópolis, SC | v. 26 | n. 10 | p. 441-456 | Mai./Ago. 2020 
una lectura minuciosa del pasaje de la Política de Aristóteles, en donde nos dice qué medidas a lo largo de la historia han sido tradicionalmente adoptadas por los tiranos para mantenerse en la tiranía.

Pues bien, que todas las medidas que la OMS ha prescrito y ordenado a las naciones integrantes de la ONU para que sus habitantes las adopten -voluntariamente o por la fuerza-, son de carácter tiránico y corresponden a estratagemas que las tiranías suelen emplear para mantener la tiranía, lo podemos ver a partir de nuestro siguiente análisis.

Son aproximadamente catorce ${ }^{23}$ las medidas que los tiranos suelen adoptar, según muestra la historia antigua, para administrar y mantener su gobierno ${ }^{24}$. A continuación presentamos en la columna izquierda tales medidas tradicionales empleadas por los tiranos, en la de en medio las medidas ordenadas por la OMS y a la derecha las consecuencias actuales que esas mismas medidas ordenadas por la OMS han generado en la población del mundo entero.

\begin{tabular}{|c|c|c|}
\hline $\begin{array}{l}\text { Medidas tradicionales para } \\
\text { preservar la tiranía según } \\
\text { Aristóteles (Pol. V 9) }\end{array}$ & $\begin{array}{l}\text { Disposiciones restrictivas o } \\
\text { prohibitivas ordenadas por } \\
\text { la } \mathrm{OMS}^{26}\end{array}$ & $\begin{array}{c}\text { Consecuencias sobre la } \\
\text { población en el mundo por } \\
\text { las medidas ordenadas por } \\
\text { la OMS }\end{array}$ \\
\hline $\begin{array}{l}1^{\text {a }} \text { Mutilar a los hombres } \\
\text { sobresalientes y eliminar a los } \\
\text { que confían en sí mismos. }\end{array}$ & $\begin{array}{l}\text { Desconfianza y miedo } \\
\text { - Lavarse las manos } \\
\text { frecuentemente con un } \\
\text { desinfectante de manos a } \\
\text { base de alcohol o con agua } \\
\text { y jabón para matar el virus } \\
\text { si este está en las manos. }\end{array}$ & $\begin{array}{l}1^{\text {a }} \text {. La censura o intimidación } \\
\text { que hay en los medios } \\
\text { electrónicos, a quien se atreve } \\
\text { a contradecir las normas, y las } \\
\text { multas a los infractores, son } \\
\text { una medida de mutilación, lo } \\
\text { cual es más evidente en } \\
\text { China. (Aunque en occidente } \\
\text { son también emblemáticos los } \\
\text { casos de Julian Assange }{ }^{31} \text {, de } \\
\text { Edward Joseph Snowden }{ }^{32} \text { y } \\
\text { del soldado Brodley } \\
\text { Manning }{ }^{33} \text { ). }\end{array}$ \\
\hline
\end{tabular}

${ }^{23}$ Cf. Pol. V 9, $1313^{\text {a }} 34-1314^{\mathrm{a}} 31$.

${ }^{24}$ Las tiranías se preservan conforme a las dos maneras más contrarias, una de las cuales es la tradicional y conforme a la cual la mayoría de los tiranos administran su gobierno. Pol. V 9, 1313 34 ss. La otra tiene el cuidado prácticamente de los mecanismos contrarios a los tradicionales $\left(1314^{\text {a }} 31\right)$.

${ }^{24}$ como en Siracusa las llamadas «confidentes» y aquellos que como escuchas enviaba Hierón, dondequiera que hubiera una reunión o asamblea.

${ }^{25}$ Política V 9, $1313^{\text {a }} 34-1314^{\text {a }} 30$.

${ }^{26}$ https://bit.ly/36EyguF (Aviso Oficial de la COVID-19 - Organización Mundial de Salud). Dichas medidas hemos de considerar que han instruidas por la oligarquía norteamericana (especialmente del Partido Demócrata y un núcleo de otras oligarquías del mundo como la inglesa, la francesa y la china del Partido Comunista) enseñoreada en la cúspide de la Organización Mundial de la Salud.

${ }^{31}$ http://queportal.fcc.unc.edu.ar/2019/08/29/julian-assange-carcel-censura-represalia-y-aquel-encuentro-con-googley-alguien-mas/

32 https://es.wikipedia.org/wiki/Edward_Snowden

${ }^{33}$ Publicado por WikiLeaks el 3 de abril de 2010, "Daño colateral" es un registro audiovisual tomado desde un helicóptero militar estadounidense cuando dispara contra un grupo de civiles en Irak, causando una decena de víctimas, entre ellas dos periodistas de Reuters. El material fílmico fue filtrado a WikiLeaks por el soldado Bradley Manning -

Revista de Direito Brasileira | Florianópolis, SC | v. 26 | n. 10 | p. 441-456 | Mai./Ago. 2020 


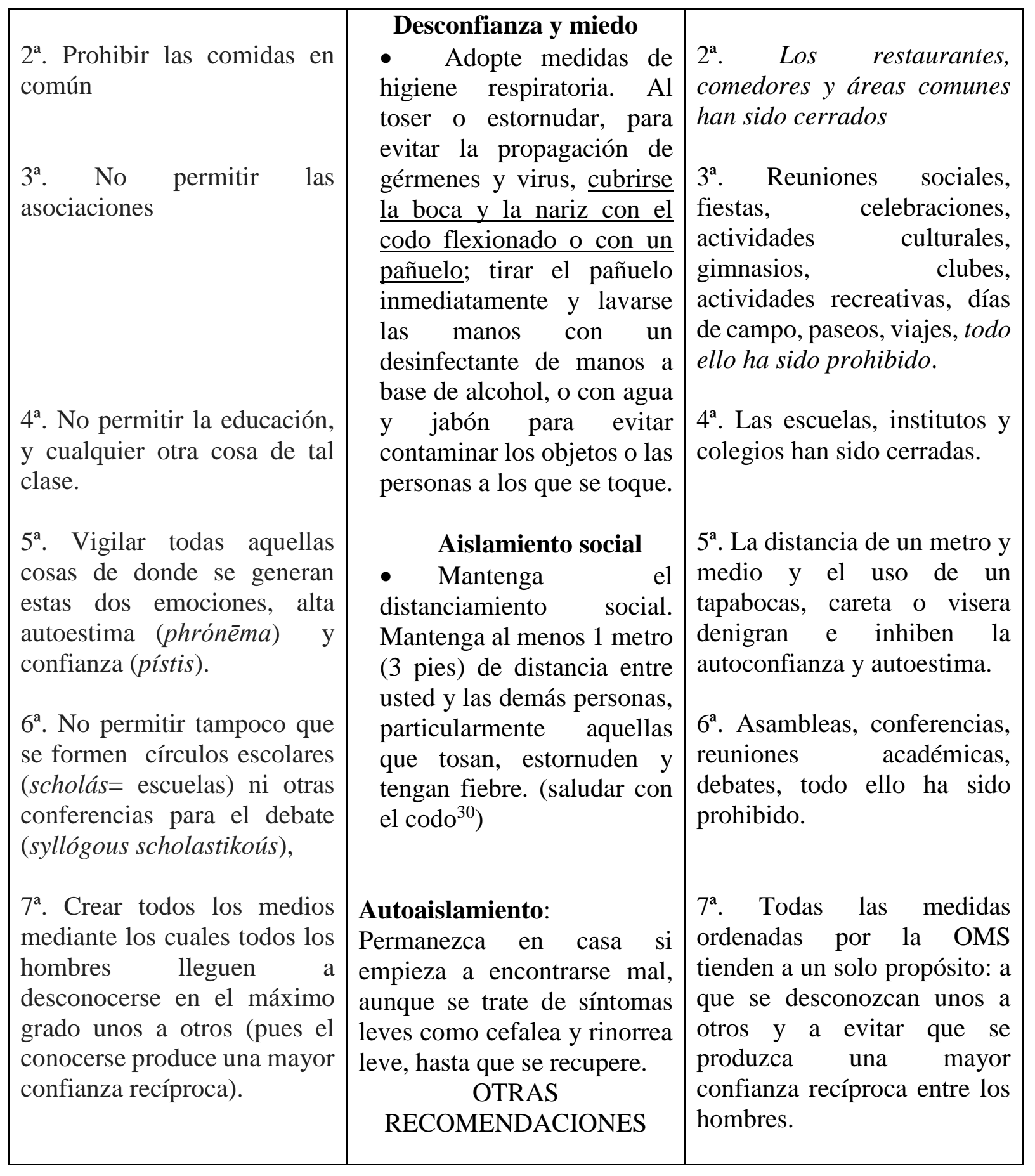

hoy Chelsea Elizabeth Manning-, quien el 21 de agosto de 2013 fue condenada por "espionaje y resistencia a la autoridad" a 35 años de cárcel y a la expulsión con deshonor del ejército estadounidense.

${ }^{30}$ OMS recuerda su recomendación de evitar saludar con el codo porque no se guarda la distancia. El director general de la OMS, Tedros Adhanom, rechazó el saludo con el codo ya que no se guarda la distancia de seguridad y puede haber transmisión del virus a través de la piel. El director de la Organización Mundial de la Salud (OMS), Tedros Adhanom Ghebreyesus, recordó este domingo, a través de un retuit, la recomendación que hizo en marzo de evitar saludarse con el codo porque no permite guardar la distancia de seguridad. "Al saludar a la gente, es mejor evitar chocar el codo porque te pones a menos de un metro de distancia de la otra persona. A mí me gusta poner la mano en el corazón para saludar a la gente estos días", aconsejó Tedros Adhanom Ghebreyesus en un mensaje publicado en su cuenta de Twitter el pasado 7 de marzo. https://aristeguinoticias.com/1309/mundo/oms-recuerda-surecomendacion-de-evitar-saludar-con-el-codo-porque-no-se-guarda-la-distancia/

Revista de Direito Brasileira | Florianópolis, SC | v. 26 | n. 10 | p. 441-456 | Mai./Ago. 2020 


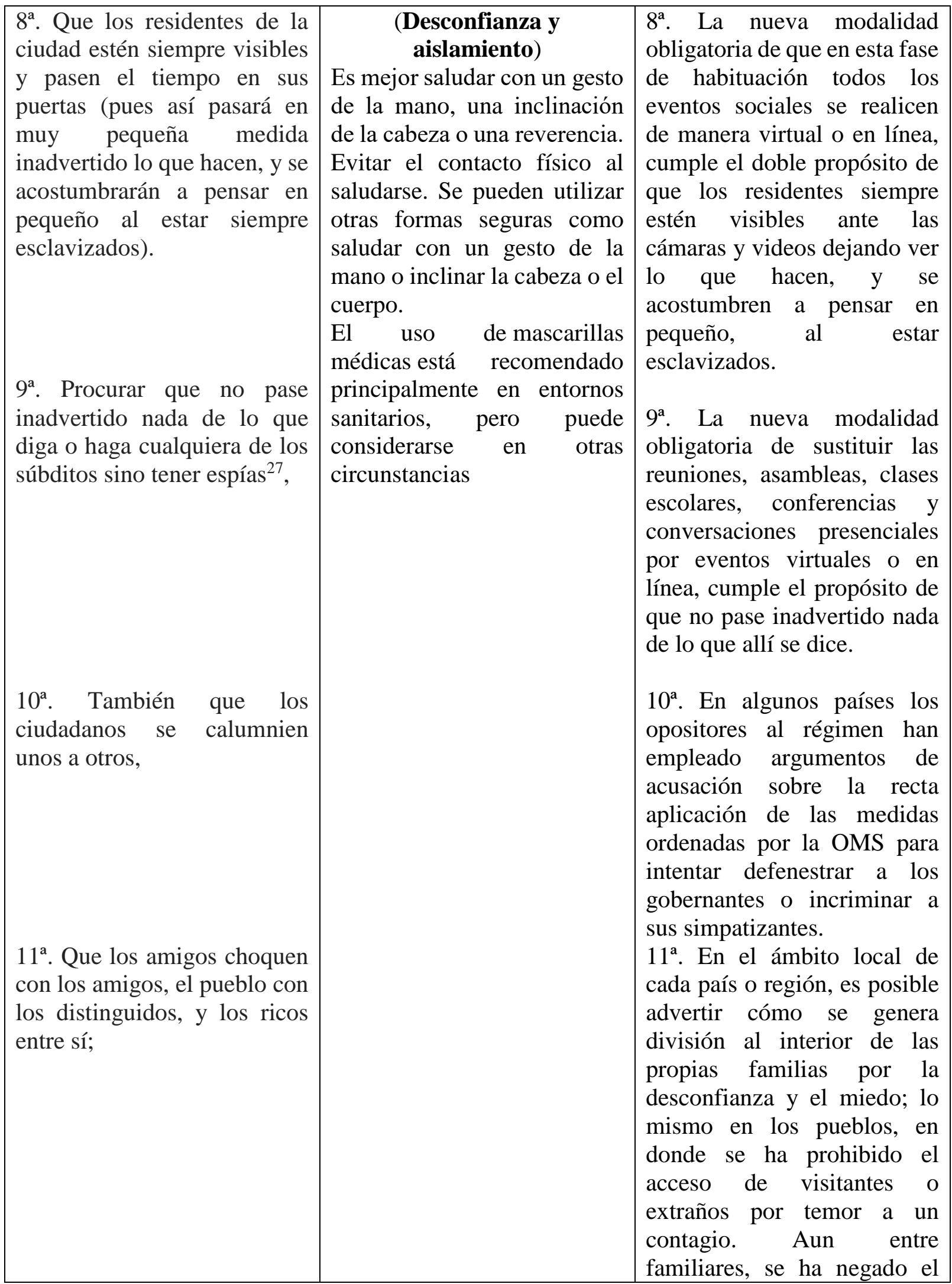

\footnotetext{
27 como en Siracusa las llamadas «confidentes» y aquellos que como escuchas enviaba Hierón, dondequiera que hubiera una reunión o asamblea (pues así hablan con menos franqueza por temor a tales espías, y si se expresan con libertad pasan menos inadvertidos).
} 


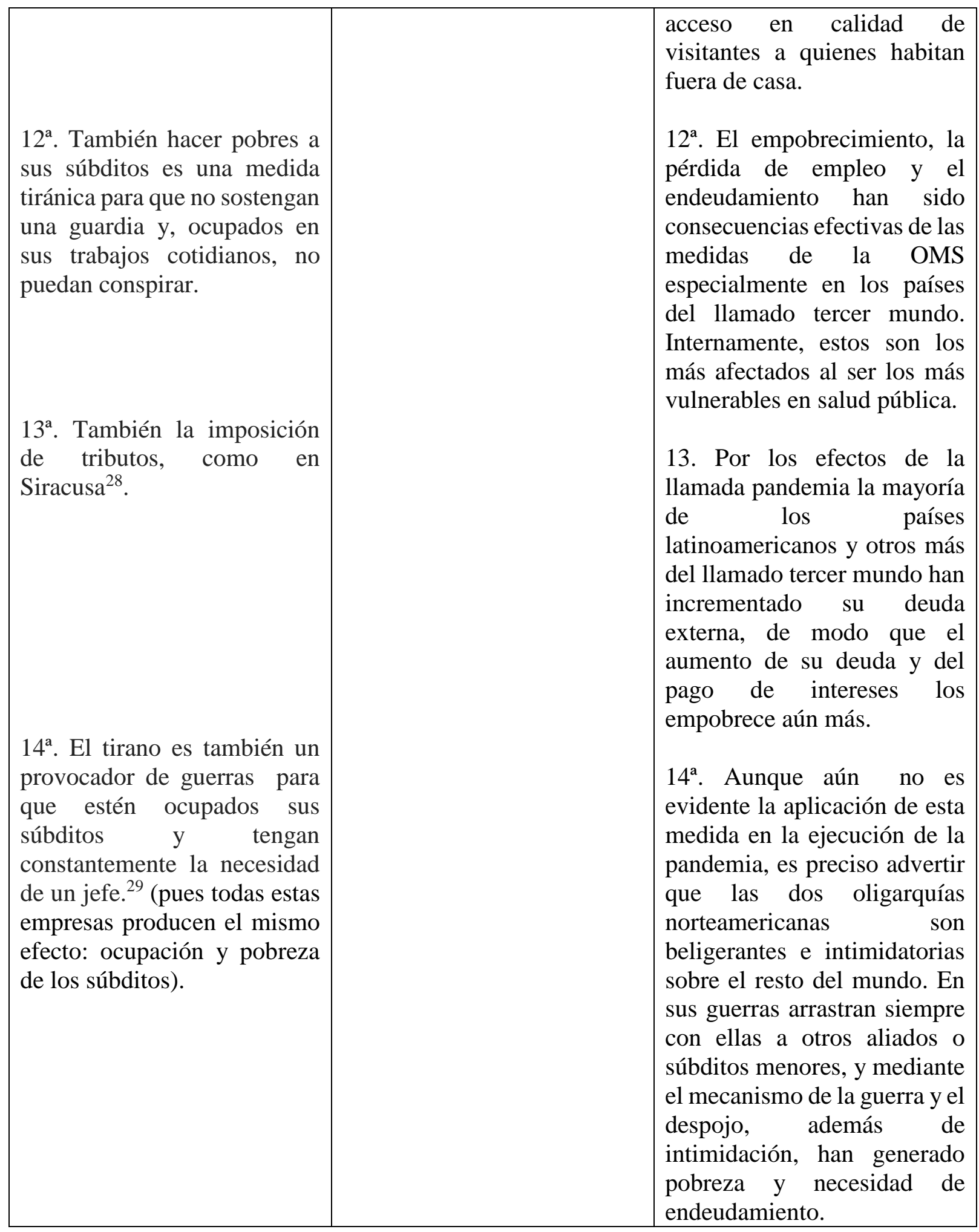

28 (donde en cinco años bajo el mando de Dionisio aportaron al tesoro toda su fortuna).

${ }^{29}$ Un ejemplo de esto son las pirámides de Egipto, las ofrendas votivas de los Cipsélidas, la construcción del templo de Zeus Olímpico por los Pisistrátidas, y entre las obras de Samos, las de Polícrates. 


\section{CONCLUSIONES PRELIMINARES} preliminar,

Por todo lo anteriormente expuesto podemos establecer, a manera de conclusión

- Que la llamada "pandemia covid-19" no es en realidad una pandemia, sino un artilugio de la oligarquía norteamericana (especialmente del Partido Demócrata y su aliado Bill Gates) y un núcleo de otras oligarquías del mundo aliadas, incluidas la inglesa y la china del Partido Comunista para someter a la población local y mundial.

- Que la finalidad de la declaración de pandemia por la OMS de ningún modo es de índole filantrópica, sino de naturaleza financiera y de dominación política sobre la humanidad entera.

- Que todas las medidas ordenadas por la OMS a los gobiernos de los países miembros de la ONU son las mismas que tradicionalmente se emplean en las tiranías por los tiranos para mantenerse en el poder y someter a sus súbditos.

- Que el uso de cubre bocas y el mantener la distancia de un metro y medio, el aislamiento social, el mandato de permanecer en casa, el que no se tenga contacto físico con nadie a no ser de manera virtual, y el que se comuniquen solo de manera virtual en sus reuniones, asambleas, conversaciones escolares o familiares, todo ello se ajusta a las intenciones de una tiranía: impedir que se engendre confianza entre unos y otros, generar desconfianza entre sí y consigo mismo, impedir que se conozcan unos a otros y vigilar mediante el espionaje lo que hacen y dicen entre sí.

- Las conferencias, clases y conversaciones en línea, de manera virtual o electrónicas tienen simultáneamente una doble finalidad, propia de la tiranía: aislar y vigilar. Pues la comunicación electrónica, al tiempo que separa, está expuesta a la vigilancia virtual. Nada de lo que se dice por los medios electrónicos pasa inadvertido y todo es a distancia.

- Al engendrar desconfianza y auto desconfianza, "filantrópicamente" se permite el uso de la tecnología para compensar con ella la prohibición de la comunicación y el contacto directos.

- Mediante el uso de cubre bocas, careta o visera y la imposición de distancia de un metro y medio entre persona y persona se denigra y afecta la autoconfianza y autoestima.

- Finalmente, para decirlo en términos aristotélicos, todas las disposiciones ordenadas por la OMS a los gobiernos de los Estados miembros de la ONU se orientan al mismo propósito al que tienden las medidas impuestas por una tiranía. La pandemia, tiende pues a esos mismos propósitos:

- La tiranía, en efecto, tiende a tres objetivos ${ }^{34}$ :

I. uno, que sus gobernados piensen en pequeño (pues un pusilánime no podría conspirar contra nadie);

II. en segundo lugar, el que desconfíen unos de otros (pues la tiranía no se disuelve hasta que algunos ciudadanos confían en sí mismos; por eso también [los tiranos] emprenden la guerra contra los excelentes, en la idea de que son dañinos para su poder, no sólo porque estos no se consideran dignos de ser gobernados despóticamente, sino también porque confían en sí mismos y en los demás y no acusan ni a los suyos ni a los demás).

III. Y en tercer lugar, la imposibilidad de las acciones (pues nadie emprende cosas imposibles, de modo que no es posible disolver la tiranía si no se dispone de poder).

\footnotetext{
${ }^{34}$ Pol. V 9, $1314^{\mathrm{a}} 15$ ss.
} 
Así pues, estos son los tres propósitos a los que tienden los planes de los tiranos, pues todas las medidas tiránicas conducen a estos principios:

I. que no confíen unos de otros,

II. que no tengan poder,

III. y que piensen en pequeño.

Tal es, pues, uno de los modos de lograr la conservación de las tiranías.

\section{REFERENCIAS BIBLIOGRÁFICAS}

\section{ARISTÓTELES,}

- (1970) Ethica Nicomachea, Recognovit brevique adnotatione critica inxtruit I. Bywater, Oxonii e typographeo clarendoniano, Oxford University Press, London.

- (1935) Magna Moralia, S. G. Stock, The Works of Aristotle, vol. IX: Metaphysics X-XIV (by H. Tredennick), Oeconomica, Magna Moralia, with an english translation by G. C.

Armstrong - --(Loeb Classical Library Nr. 287), London.

- (2005) Politics, transl. by H. Rackham, London: Loeb Classical Library.

ARAIZA, Jesús Manuel (2020), "La pandemia del covid-19: una interpretación desde la ciencia política”, en COVID-19 E SEUS PARADOXOS, Organizadores Liton Lanes Pilau Sobrinho, Claide Calgaro y Leonel Severo Rocha, UNIVALI, Brasil.

BHAKDI, S. \& Reiss, K. (2016). Schreckgespenst Infektionen. Berlin: Goldegg Verlag. Bode, S. (2004). Die vergessene Generation. Die Kriegskinder brechen ihr Schweigen. Stuttgart: Klett-Cotta Verlag.

BODE, S. (2009). Kriegsenkel. Die Erben der vergessenen Generation. Stuttgart: Klett-Cotta Verlag.

ENGELBRECHT, T. \& Köhnlein, C. (2020). Virus-Wahn. Lahnstein: emu-Verlags- und Betriebs-GmbH.

FISCHER, G. \& Riedesser, P. (1998). Lehrbuch der Psychotraumatologie. München: UTB Verlag.

GRESENS, R. (2016). Intuitives Stillen. Dem eigenen Gefühl vertrauen. München: Kösel Verlag. Maaz, H.-J. (2017). Das falsche Leben. Ursachen und Folgen unserer normopathischen Gesellschaft. München: Beck Verlag.

MÖLLING, K. (2020). Viren: Supermacht des Lebens. München: Beck Verlag.

MÜNZING-RUF, I. (1991). So stärken Sie Ihr Immunsystem. München: Heyne Verlag.

ORWELL, G. (2008). Nineteen Eighty-Four. London: Penguin Books.

REISS, C. \& Bhakdi, S. (2020). Corona Fehlalarm. Zahlen, Daten und Hintergründe. Berlin: Goldegg Verlag. 
RUPPERT, F. (Hg.) (2014). Frühes Trauma. Schwangerschaft, Geburt und erste Lebensjahre. Stuttgart: Klett-Cotta Verlag.

RUPPERT, F. \& Banzhaf, H. (Hg.) (2017). Mein Körper, mein Trauma, mein Ich. Anliegen aufstellen, aus der Traumabiografie aussteigen. München: Kösel Verlag.

RUPPERT, F. (2018). Wer bin Ich in einer traumatisierten Gesellschaft? Wie Täter-OpferDynamiken unser Leben bestimmen und wie wir daraus aussteigen. Stuttgart: Klett-Cotta Verlag.

VESTER, F. (1991). Phänomen Stress. München: dtv-Verlag.

WATZLAWICK, P. (2018). Wie wirklich ist die Wirklichkeit? Wahn, Täuschung, Verstehen. München: Piper Verlag.

WERNICKE, J. (Hg.) (2017). Lügen die Medien? Propaganda, Rudeljournalismus und der Kampf um die öffentliche Meinung. Frankfurt/M.: Westend Verlag.

WODARG, W. (2015). Falscher Alarm: Die Schweinegrippe-Pandemie. In Borch-Jacobsen, M. (Hg.) (2015). BIG PHARMA, S. 310-325. München: Piper Verlag. 